\title{
Teaching Models of Translation Courses Aiming at Fostering Critical Thinking Skills
}

\author{
Hong Liu \\ College of Foreign Languages and Literature, Wuhan Donghu University, Wuhan Hubei, 430212, China
}

Keywords: critical thinking; translation; teaching models

\begin{abstract}
Critical thinking skill is one of the comprehensive qualities for college students. It is the basis of fostering creative talents. Fostering student's creative thinking is an important project related to the country's developing strategies on education. Translation teaching should be paid great attention; at the same time, it needs to form a creative-oriented teaching environment. On the basis of fully understanding the theory of critical thinking, theoretical teaching concept of critical thinking can be penetrated into the curriculum designing, teaching idea, teachers' literacy, teaching evaluation and training target, so as to nurture students to become critical and innovative talents. Thus, it can inject new elements and motivation for the sustainable development of translation studies. Based on Bloom's cognitive hierarchy theory, this paper combines the cultivation of critical thinking skills and translation teaching, which can not only enrich the literature on critical thinking, but also offer a guide for similar studies and translation teaching methods. Furthermore, it can promote the improvement of the effect of translation teaching, which eventually leads to critical transformation and upgrade of China's higher foreign language education.
\end{abstract}

\section{Introduction}

The higher education law of contemporary China stipulates that "the task of higher education is to cultivate senior specialized personnel with innovative spirit and practical ability."The foundation of innovative spirit and practical ability is critical thinking. Obviously, the cultivation of critical thinking is an eternal topic of higher education. At present, higher education in China experiences a new round of educational reform, oriented in connotative development and quality improvement of education. Therefore, the importance of critical thinking is more highlighted. Although in recent years, domestic scholars have a certain understanding of critical thinking, but as a hot topic in recent years, the research about critical thinking is not very mature, there is a big research space. Over the past decade, the understanding of critical thinking in China has made great development, which is not only reflected in its connotation research skills, but also reflected in people's recognition of the important position of critical thinking in the talent training. In order to cultivate and improve the critical ability of students majoring in English, the researchers have conducted experiments on multiple aspects of English learning. But there are some problems and shortcomings. Can the various approaches of cultivating students' ability of thinking and reasoning, which researchers work hard to study, be really applied to the masses of teaching faculty and scholars? When can these results be changed into a framework of principles to guide the first line of educational workers, and then effectively and extensively improve students' problems of “critical-absence"? How to cultivate students' ability of critical thinking in various courses, especially in translation courses? These questions remain to be considered. This article aims to explore the translation teaching models based on the theory of Bloom's taxonomy.

\section{The theory of Bloom's taxonomy and critical thinking}

Bloom's taxonomy is a set of three hierarchical models used to classify educational learning objectives into levels of complexity and specificity. The three lists cover the learning objectives in cognitive, affective and sensory domains. The cognitive domain list has been the primary focus of most traditional education and is frequently used to structure curriculum learning objectives, 
assessments and activities. In the original version of the taxonomy, the cognitive domain is broken into the following six levels of objectives. In the 2001 revised edition of Bloom's taxonomy, the levels are slightly different: Remember, Understand, Apply, Analyze, Evaluate, Create (rather than Synthesize).Bloom's taxonomy serves as the backbone of many teaching philosophies, in particular, those that lean more towards skills rather than content. These educators view content as a vessel for teaching skills. The emphasis on higher-order thinking inherent in such philosophies is based on the top levels of the taxonomy including analysis, evaluation, synthesis and creation. Bloom's taxonomy can be used as a teaching tool to help balance assessment and evaluative questions in class, assignments and texts to ensure all orders of thinking are exercised in students' learning, including aspects of information searching.

Critical thinking is the objective analysis of facts to form a judgment. The subject is complex, and there are several different definitions which generally include the rational, skeptical, unbiased analysis or evaluation of factual evidence. Critical thinking was described by Richard W. Paul as a movement in two waves (1994). The "first wave" of critical thinking is often referred to as a "critical analysis" that is clear, rational thinking involving critique. Its details vary amongst those who define it. According to Barry K. Beyer (1995), critical thinking means making clear, reasoned judgments. During the process of critical thinking, ideas should be reasoned, well thought out, and judged. The U.S. National Council for Excellence in Critical Thinking defines critical thinking as the intellectually disciplined process of actively and skillfully conceptualizing, applying, analyzing, synthesizing, or evaluating information gathered from, or generated by, observation, experience, reflection, reasoning, or communication, as a guide to belief and action.Critical thinking is significant in academics due to being significant in learning. Critical thinking is significant in the learning process of internalization, in the construction of basic ideas, principles, and theories inherent in content. And critical thinking is significant in the learning process of application, whereby those ideas, principles, and theories are implemented effectively as they become relevant in learners' lives. Each discipline adapts its use of critical thinking concepts and principles. The core concepts are always there, but they are embedded in subject-specific content. For students to learn content, intellectual engagement is crucial. All students must do their own thinking, their own construction of knowledge. Good teachers recognize this and therefore focus on the questions, readings, activities that stimulate the mind to take ownership of key concepts and principles underlying the subject. Historically, teaching of critical thinking focused only on logical procedures such as formal and informal logic. This emphasized to students that good thinking is equivalent to logical thinking. However, a second wave of critical thinking, urges educators to value conventional techniques, meanwhile expanding what it means to be a critical thinker. In 1994, Kerry Walters compiled a conglomeration of sources surpassing this logical restriction to include many different authors' research regarding connected knowing, empathy, gender-sensitive ideals, collaboration, world views, intellectual autonomy, morality and enlightenment. These concepts invite students to incorporate their own perspectives and experiences into their thinking.

\section{Teaching translation oriented towards the cultivation of critical thinking skills}

First of all, in order to improve students' skills of critical thinking, new teaching textbooks should be compiled to improve the quality of teaching. During the process of compiling textbooks, the teaching materials and exercises should be fully considered and carefully chosen, in order that it can improve students' critical thinking skills. Textbooks are the basis for teaching and also the key to ensure the quality of teaching. When the textbook is written, for the same materials, different translations can be set for students to discuss and study. In addition, you can set the translation tasks which can combine translation theories and practices. With the same theory, we can conduct comparative analysis of different translation versions. With different theoretical horizons of translation studies, we can discuss the same translation material. This can help students think, analyze different theories and various translation versions, which can improve their learning effect.

Second, in the choice of translation material in and out the classroom, we should follow the principle of critical thinking training. According to the students' interest, knowledge level and social 
needs, teachers can elaborately design various types of tasks, including sentence translation, text translation, translation comparison and evaluation to cultivate the students' translation ability. The difficulty of the task must be moderate. The translation materials selected by the teachers are mainly texts' translation, and the single sentences are the auxiliary, which can cultivate the students' sense of discourse translation. Teachers should also consider the similarities and differences between Chinese and English languages in cultural tradition and syntactic expression, while taking into account the ability of students to analyze the two languages in grammar and logic.

First of all, the classroom task is assigned to students without any preparation. In the translation teaching, teachers should pay attention to the cultivation of students' understanding, analysis and judgment ability, and infiltrate relevant translation theories and techniques. The translation materials chosen by the teachers should not completely be the contents of the textbooks. Such translation practice is not suitable for the cultivation of students' thinking ability. The teachers should select effective and diversified translation materials. After analyzing wording, sentence structure, grammar, after the understanding and analysis, teachers should also evaluate the whole chapter. Teachers should encourage students to think seriously, analyze carefully, judge boldly. When the teacher comments students' translation, they can grasp the difficult points and the key points. In addition, while affirming the advantages of students' translation, teachers should also point out deficiencies so that students can avoid weak points and improve their translation. For the same material, the students will have different views. Indeed, the students can try to improve their own independent thinking and understanding, analysis, and judgment, especially boldly put forward their own views, which can improve their critical thinking.

Secondly, set aside some translation assignments without any reference. At present, various online translation and search function is more convenient to use, if the extracurricular translation tasks assigned by the teacher is old or with more existing versions of the translation, it is not conducive for students to put forward new ideas and reflect their own level of translation. If the tasks assigned by the teacher are with no relevant reference, the students have to do their best to think about and analyze, so that the appropriate translation can be put forward. Such a way can help students understand and analyze, develop their ability to judge and propose their own opinions.

\section{Teaching assessment}

Change the single evaluation system, enrich the detection means. At present, the evaluation system of translation courses in colleges and universities is relatively monotonous. In terms of translation courses, the traditional test method is the final exam. The contents of the final exam lack creativity, and the form is the same for many years. Most of the tests come from textbooks or after-school exercises, so students can easily pass the test. This not only does not improve students' ability to think, but is harmful to students' learning. If you want to examine poetry translation theory of "three beauty", you can choose two or three translation versions of a poem and let the students write translation criticism from the angle of theory of "three beauty", from three aspects including "sound, form and meaning" to analyze the original poem, conduct the comparative analysis of different translations and the original poems and translations between comparative analysis.

\section{Conclusions}

Based on the theory of Bloom's taxonomy, the six processes including memory, grasp, manipulate, analyze, evaluate, create, should be unified and can be applied to translation courses, which can develop students critical thinking skills. While strengthening students' language basic skills, translation courses should also reform the teaching method, improve teaching content, promote teaching progress, advance the teaching idea, and strengthen the practice teaching to improve students' critical thinking skills. The colleges and universities can only improve the ability of the teachers and students to improve their ability of thinking by examining and discovering problems, reforming teaching methods and implementing more effective evaluation measures. 


\section{References}

[1] Anderson L W, Krathwohl D R. A Taxonomy for Learning, Teaching and Assessing: A Revision of Bloom's Taxonomy of Educational Objectives [J]. European Legacy, 2001, 114(458):1013-1014.

[2] David R. Krathwohl. A Revision of Bloom's Taxonomy: An Overview [J]. Theory into Practice, 2002, 41(4):212-218.

[3] Glaser E M. An Experiment in the Development of Critical Thinking [M]. An experiment in the development of critical thinking. AMS Press, 2005.

[4] Li Y. On Teaching Translation in a Textual Perspective [J]. Chinese Translators Journal, 2003.

[5] Lloyd M, Nan B. Thinking Critically about Critical Thinking in Higher Education [J]. International Journal for the Scholarship of Teaching \& Learning, 2010, 4(2). 